\title{
Is contact allergy to disperse dyes and related substances associated with textile dermatitis?
}

\author{
K. Ryberg, ${ }^{\star} \dagger$ A. Goossens, $\$$ M. Isaksson, ${ }^{\star}$ B. Gruvberger, ${ }^{*}$ E. Zimerson, ${ }^{*}$ F. Nilsson,§ J. Björk,§ M. Hindsén*
} and M. Bruze*

*Department of Occupational and Environmental Dermatology, Lund University, Malmö University Hospital, Malmö, Sweden

$\dagger$ Department of Dermatology, NÄL, S-461 85 Trollhättan, Sweden

†Department of Dermatology, Contact Allergy Unit, University Hospital, K.U. Leuven, Leuven, Belgium

$\S$ Competence Centre for Clinical Research, Lund University Hospital, Lund University, Lund, Sweden

\section{Summary}

Correspondence

Kristina Ryberg.

E-mail: kristina.morgardt-ryberg@med.lu.se

Accepted for publication

26 September 2008

Key words

contact allergy, disperse dyes,

para-phenylenediamine, questionnaire,

textile dye mix, textile-related skin problems

Conflicts of interest

None declared.

DOI $10.1111 / j .1365-2133.2008 .08953 . x$
Background Disperse dyes (DDs) are the most common sensitizers among textile dyes, but there is little knowledge of the clinical relevance of positive patch test reactions.

Objective To investigate if patient-reported textile-related skin problems can be explained by contact allergy to eight different DDs and/or to chemically related substances, by occupation or by atopic constitution, and if the skin problems are influenced by age or sex.

Methods A questionnaire on textile-related skin problems was answered by 858 of 982 consecutively patch tested patients in Malmö, Sweden and in Leuven, Belgium. The baseline series used for patch testing was supplemented with a textile dye mix (TDM) consisting of the eight DDs and with the separate dyes. The association between textile-related skin problems and contact allergy to the DDs and other risk factors was investigated using multiple logistic regression analysis.

Results Eighteen per cent of the patients suspected textiles as a cause of their skin problems. Atopic constitution and female sex were risk factors for skin reactions. Synthetic materials were the most common textiles to give skin problems. A significant association was found between self-reported textile-related skin problems and contact allergy to para-phenylenediamine (PPD) [adjusted odds ratio (OR) $2 \cdot 1 ; 95 \%$ confidence interval (CI) $1 \cdot 0-4 \cdot 3]$. A similar, but more imprecise, adjusted OR was found for TDM (OR $1 \cdot 9 ; 95 \%$ CI $0 \cdot 57-5 \cdot 6)$. Contact allergy to black rubber mix was too rare to be evaluated.

Conclusions Contact allergy to PPD was a more prevalent indicator for skin reactions to textiles than the TDM used in this study.
Textile dermatitis, i.e. skin manifestations due to clothing and other textiles, can be caused by irritant reactions to textile fibres or by contact allergy to textile dyes and finishing chemicals. ${ }^{1-3}$ The prevalence of textile dermatitis in various countries is not known. Disperse dyes (DDs) are the most common sensitizers among textile dyes, but contact allergy to DDs may go undiagnosed because the clinical picture does not give rise to suspicion of textile dermatitis. ${ }^{4}$ Some DDs known to cause contact allergy are included in textile patch test screening series but not in commercially available baseline patch test series, 5,6 whereas para-phenylenediamine (PPD), which historically has been considered to be a screening allergen for textile dye dermatitis, ${ }^{7}$ is included in most baseline patch test series.
In a previous study we found that contact allergy to DDs is quite common in Sweden, with $1.5 \%$ of 3325 consecutively patch tested patients reacting positively to a textile dye mix (TDM) consisting of eight DDs: Disperse Blue (DB) 35, 106 and 124; Disperse Yellow (DY) 3; Disperse Orange (DO) 1 and 3; and Disperse Red (DR) 1 and $17 .{ }^{8}$ As this study was retrospective, information about the clinical relevance of a positive TDM patch test reaction was not always available.

The aim of the present study was to investigate if clinical signs or symptoms suspected of being caused by textiles could be explained by contact allergy to the TDM and/or to chemically related substances, such as PPD and black rubber mix (BRM), or by other factors, such as occupation or atopic 
Health Care, Göteborg, Sweden) were used in Leuven. The test chambers were left on the back for $48 \mathrm{~h}$ and readings followed the guidelines of the International Contact Dermatitis Research Group. ${ }^{9}$ Readings were performed in Malmö on day 3 or 4 and on day 7 or 8 , and in Leuven on days 2 and 4 and sometimes on day 7. Only the patch test reactions registered on day 3 or 4 were used for registration in the present study.

The patients were all patch tested with the baseline patch test series of the respective departments. The baseline series used in the Malmö department was purchased from Chemotechnique Diagnostics, Vellinge, Sweden. It included formaldehyde $1.0 \%$ in water, PPD $1 \% \mathrm{w} / \mathrm{w}$ in petrolatum (pet.) and BRM $0.6 \% \mathrm{w} / \mathrm{w}$ (pet.), consisting of three components, $\mathrm{N}, \mathrm{N}^{\prime}$-diphenyl-1,4-phenylenediamine, N-cyclohexyl- $\mathrm{N}^{\prime}$-phenyl1,4-phenylenediamine and $\mathrm{N}$-isopropyl- $\mathrm{N}^{\prime}$-phenyl-1,4-phenylenediamine. The department in Leuven bought their baseline patch test series, including PPD $1 \% \mathrm{w} / \mathrm{w}$ (pet.) and formaldehyde $1 \%$ in water, from Trolab, Reinbek, Germany. The BRM $0 \cdot 6 \% \mathrm{w} / \mathrm{w}$ (pet.) used in Leuven was made by Chemotechnique Diagnostics. The TDM and the eight separate components in the mix were temporarily included in the baseline series of both centres. The composition of the dye mix was identical to a mix used previously by Dr Francisco Brandão, Almada, Portugal (personal communication) and consisted of DB 35, DY 3, DO 1 and 3, DR 1 and 17 , all $0.5 \% \mathrm{w} / \mathrm{w}$ (pet.), in addition to DB 106 and DB 124, both $0 \cdot 1 \% \mathrm{w} / \mathrm{w}$ (pet.), giving a total concentration of $3 \cdot 2 \% \mathrm{w} / \mathrm{w}$. The dyes were bought from Chemotechnique Diagnostics, and the test preparations were made at the department in Malmö. The mix and the test preparations of the eight dyes were made from the same batches.

\section{Statistical analysis}

The results were analysed using SPSS version 12.0 (SPSS Inc., Chicago, IL, U.S.A.). Fisher's exact test and logistic regression were used and we regarded two-sided $\mathrm{P}<0.05$ as statistically significant. Odds ratios (OR), 95\% confidence intervals (CI) and $\mathrm{P}$-values for a positive answer to the question about having textile-related skin problems were calculated in a multiple logistic regression analysis with age, sex, childhood eczema, occupation and contact allergies as possible predictors. The model was simplified step-by-step by removal of those terms that were least significant in a likelihood-ratio test, unless the removal of an insignificant term changed the remaining effect estimates by $10 \%$, until only significant or otherwise important terms remained.

\section{Results}

\section{Patch test reactions}

The patients who tested positively to the TDM and/or to the eight separate components as well as simultaneous test reactions to PPD and BRM are shown in Table 2. Twenty out of 982 patients $(2 \%)$ tested positively to the TDM. Thirteen of the 20 TDM-positive patients tested positively to at least one of the components in the mix. The contact allergy rate to the separate components was in the range of one to six patients, with DO 1 as the most frequent, followed by DO 3. Most of the TDM reactions were weak $(+$ or ++$)$. Two patients allergic to DO 1 and DO 3, respectively, did not test positively to the mix. Five per cent of the patients tested positively to PPD and $1 \%$ to BRM. A statistically highly significant interaction was seen between positive test results to both PPD and TDM $(\mathrm{P}<0.001)$, and between the patients testing positively to both TDM and BRM $(\mathrm{P}<0.001)$.

\section{Statistically significant associations}

Eight per cent of the patients reporting skin problems from textiles were allergic to PPD compared with $4 \%$ of those without intolerance to textiles ( $\mathrm{P}=0.057$; Table 3$)$. However, in the multiple logistic regression analysis contact allergy to PPD was found to be an important risk factor for textile-related skin problems with OR 2.14 (CI 1.01-4.31; P = 0.039; Table 4).

Eighteen per cent of the patients suspected textiles as a possible cause of their skin problems, $23 \%$ of the women and $12 \%$ of the men $(P<0.001)$. Sex was a risk factor in the multiple logistic regression analysis, where females had an increased risk of reporting problems from textiles. Increasing age was also an important predictor of the tendency to report problems from textiles. The results of the multiple logistic regression analysis can be seen in Table 4 .

Twenty-two per cent of the patients had had eczema as a child, $27 \%$ of the females compared with $14 \%$ of the males $(\mathrm{P}<0.001$; Table 3); $34 \%$ of those suspecting textiles had had eczema as a child compared with 19\% without textile-related skin problems $(\mathrm{P}<0.001$; Table 5). In the multiple logistic regression analysis childhood eczema was also found to be an important risk factor for textile-related skin problems (Table 4).

Fifty-eight per cent of the patients reporting intolerance to textiles suspected synthetic materials as a cause, followed by wool in $35 \%$, cotton in $22 \%$ and silk in $6 \%$. Forty-one per cent of the women with skin problems from textiles reported intolerance to wool compared with $19 \%$ of the men $(P=0.009)$. Thirteen per cent of the women who suspected intolerance to synthetic materials were allergic to PPD compared with $2 \%$ of women without skin problems from such textiles $(\mathrm{P}=0.037)$. No association was found between skin problems from various types of textiles and contact allergy to TDM or BRM. Forty-seven per cent of the patients who had had childhood eczema reported wool as a cause of their rash/itch compared with $29 \%$ of those without eczema in childhood $(P=0.032)$. Except for intolerance to wool, no association was found between childhood eczema and skin problems from various types of textiles.

\section{Statistically nonsignificant associations}

Although not statistically significant, $3 \cdot 2 \%$ of those reporting skin problems were allergic to TDM compared with $1 \cdot 7 \%$ 
110 Disperse dyes and textile dermatitis, K. Ryberg et al.

Table 2 Patch test results in the 60 patients with a positive patch test to the textile dye mix (TDM), the different disperse dyes, para-phenylenediamine (PPD) and/or to black rubber mix (BRM)

\begin{tabular}{|c|c|c|c|c|c|c|c|c|c|c|c|c|}
\hline Sex & $\begin{array}{l}\text { Age } \\
\text { (years) }\end{array}$ & $\begin{array}{l}\text { TDM } \\
3 \cdot 2 \%\end{array}$ & $\begin{array}{l}\text { DB } 106 \\
0 \cdot 1 \%\end{array}$ & $\begin{array}{l}\text { DB } 124 \\
0 \cdot 1 \%\end{array}$ & $\begin{array}{l}\text { DB } 35 \\
0.5 \%\end{array}$ & $\begin{array}{l}\text { DY } 3 \\
0.5 \%\end{array}$ & $\begin{array}{l}\text { DO } 1 \\
0.5 \%\end{array}$ & $\begin{array}{l}\text { DO } 3 \\
0.5 \%\end{array}$ & $\begin{array}{l}\text { DR } 1 \\
0.5 \%\end{array}$ & $\begin{array}{l}\text { DR } 17 \\
0.5 \%\end{array}$ & $\begin{array}{l}\text { PPD } \\
1 \%\end{array}$ & $\begin{array}{l}\text { BRM } \\
0.6 \%\end{array}$ \\
\hline F & 16 & +++ & & & & +++ & +++ & + & ++ & & +++ & ++ \\
\hline M & 59 & +++ & & & & & +++ & + & & & & +++ \\
\hline $\mathrm{M}$ & 30 & ++ & & & & & + & & & + & +++ & \\
\hline F & 52 & ++ & & & ++ & ++ & & & ++ & ++ & ++ & ++ \\
\hline $\mathrm{M}$ & 67 & ++ & & & & + & & & & & ++ & \\
\hline F & 53 & ++ & & & & & & & + & & ++ & \\
\hline F & 49 & ++ & ++ & ++ & & & . & & & + & & \\
\hline F & 28 & ++ & & & & & & & & & & \\
\hline F & 48 & + & & & & & + & & & & +++ & \\
\hline F & 51 & + & & & & & & & & & +++ & \\
\hline F & 64 & + & & & & & & & & & ++ & \\
\hline F & 69 & + & & & & & & & & & + & \\
\hline F & 24 & + & & & & & & + & & & & \\
\hline $\mathrm{M}$ & 28 & + & & & & . & + & & . & 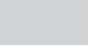 & & + \\
\hline F & 87 & + & & & & & & & & & & \\
\hline F & 39 & + & + & + & & & & & & & & \\
\hline $\mathrm{M}$ & 63 & + & & & & & & & & & & \\
\hline $\mathrm{M}$ & 57 & + & & & & & & & & & & \\
\hline F & 41 & + & & & & + & & & + & & & \\
\hline $\mathrm{F}$ & 22 & + & & & & & & + & & & & \\
\hline F & 26 & & & & & & ++ & & & & & \\
\hline $\mathrm{M}$ & 24 & & & & & & & & & & +++ & +++ \\
\hline F & 43 & & & & & & & & & & +++ & \\
\hline F & 42 & & & & & & & & & & +++ & \\
\hline F & 24 & & & & & & & & & & +++ & \\
\hline F & 67 & & & & & & & & & & +++ & \\
\hline $\mathrm{M}$ & 67 & & & & & & & & & & ++ & ++ \\
\hline $\mathrm{M}$ & 24 & & & & & & & + & & & ++ & + \\
\hline F & 44 & & & & & & & & & & ++ & \\
\hline F & 64 & & & & & & & & & & ++ & \\
\hline F & 22 & & & & & & & & & & ++ & \\
\hline F & 45 & & & & & & & & & & ++ & \\
\hline $\mathrm{F}$ & 59 & & & & & & & & & & ++ & \\
\hline F & 48 & & & & & & & & & & ++ & \\
\hline F & 39 & & & & & & & & & & ++ & \\
\hline F & 27 & & & & & & & & & & ++ & \\
\hline M & 42 & & & & & & & & & & ++ & \\
\hline $\mathrm{M}$ & 59 & & & & & & & & & & ++ & \\
\hline M & 63 & & & & & & & & & & ++ & \\
\hline M & 28 & & & & & & & & & & ++ & \\
\hline $\mathrm{F}$ & 42 & & & & & & & & & & ++ & \\
\hline F & 13 & & & & & & & & & & ++ & \\
\hline M & 41 & & & & & & & & & & + & \\
\hline F & 39 & & & & & & & & & & + & \\
\hline F & 28 & & & & & & & & & & + & \\
\hline F & 57 & & & & & & & & & & + & \\
\hline F & 44 & & & & & & & & & & + & \\
\hline F & 46 & & & & & & & & & & + & \\
\hline F & 44 & & & & & & & & & & + & \\
\hline F & 45 & & & & & & & & & & + & \\
\hline F & 54 & & & & & & & & & & + & \\
\hline F & 61 & & & & & & & & & & + & \\
\hline $\mathrm{M}$ & 45 & & & & & & & & & & + & \\
\hline $\mathrm{M}$ & 43 & & & & & & & & & & + & \\
\hline $\mathrm{M}$ & 43 & & & & & & & & & & + & \\
\hline M & 55 & & & & & & & & & & + & \\
\hline
\end{tabular}


Table 2 (Continued)

\begin{tabular}{|c|c|c|c|c|c|c|c|c|c|c|c|c|}
\hline Sex & $\begin{array}{l}\text { Age } \\
\text { (years) }\end{array}$ & $\begin{array}{l}\text { TDM } \\
3 \cdot 2 \%\end{array}$ & $\begin{array}{l}\text { DB } 106 \\
0 \cdot 1 \%\end{array}$ & $\begin{array}{l}\text { DB } 124 \\
0 \cdot 1 \%\end{array}$ & $\begin{array}{l}\text { DB 35 } \\
0.5 \%\end{array}$ & $\begin{array}{l}\text { DY } 3 \\
0.5 \%\end{array}$ & $\begin{array}{l}\text { DO } 1 \\
0.5 \%\end{array}$ & $\begin{array}{l}\text { DO } 3 \\
0.5 \%\end{array}$ & $\begin{array}{l}\text { DR } 1 \\
0.5 \%\end{array}$ & $\begin{array}{l}\text { DR } 17 \\
0.5 \%\end{array}$ & $\begin{array}{l}\text { PPD } \\
1 \%\end{array}$ & $\begin{array}{l}\text { BRM } \\
0.6 \%\end{array}$ \\
\hline F & 72 & & & & & & & & & & + & \\
\hline $\mathrm{M}$ & 70 & & & & & & & & & & & + \\
\hline $\mathrm{M}$ & 47 & & & & & & & & & & & + \\
\hline $\mathrm{M}$ & 53 & & & & & & & & & & & + \\
\hline
\end{tabular}

,,++++++ , Test reactivity. Empty box indicates a negative reaction. DB, Disperse Blue; DY, Disperse Yellow; DO, Disperse Orange; DR, Disperse Red.

Table 3 The answers to the questionnaire given by the 858 patients who participated in the questionnaire, divided by sex and patch test results

\begin{tabular}{|c|c|c|c|c|c|c|c|c|c|c|}
\hline & \multicolumn{10}{|c|}{ Answers to the questionnaire } \\
\hline & \multicolumn{3}{|l|}{ Yes, n (\%) } & \multicolumn{3}{|c|}{ No/don't know, n (\%) } & \multicolumn{4}{|c|}{ P-values, positive answers vs. negative } \\
\hline & $\mathrm{W}$ & $\mathrm{M}$ & $\mathrm{W}+\mathrm{M}$ & $\mathrm{W}$ & M & $\mathrm{W}+\mathrm{M}$ & $\mathrm{W}$ & M & $\mathrm{W}+\mathrm{M}$ & $\mathrm{W} / \mathrm{M}$ \\
\hline \multicolumn{11}{|c|}{ Have you ever had a rash/itch from textiles? } \\
\hline All $(\mathrm{n}=857)$ & $112(22 \cdot 5)$ & $43(11 \cdot 9)$ & $155(18 \cdot 1)$ & & & & & & & $<0.001$ \\
\hline TDM pos. & $3(2 \cdot 7)$ & $2(4 \cdot 7)$ & $5(3 \cdot 2)$ & $8(2 \cdot 1)$ & $4(1 \cdot 3)$ & $12(1 \cdot 7)$ & $>0 \cdot 3$ & $0 \cdot 153$ & $0 \cdot 211$ & \\
\hline PPD pos. & $9(8 \cdot 1)$ & $3(7 \cdot 0)$ & $12(7 \cdot 7)$ & $17(4 \cdot 4)$ & $11(3 \cdot 5)$ & $28(4 \cdot 0)$ & $0 \cdot 148$ & $0 \cdot 227$ & 0.057 & \\
\hline BRM pos. & 0 & $1(2 \cdot 3)$ & $1(0 \cdot 6)$ & $1(0 \cdot 3)$ & $7(2 \cdot 2)$ & $8(1 \cdot 1)$ & $>0 \cdot 3$ & $>0 \cdot 3$ & $>0 \cdot 3$ & \\
\hline \multicolumn{11}{|c|}{ Have you had eczema as a child? } \\
\hline All $(\mathrm{n}=852)$ & $133(27 \cdot 0)$ & $51(14 \cdot 2)$ & $184(21 \cdot 6)$ & & & & & & & $<0.001$ \\
\hline TDM pos. & $3(2 \cdot 3)$ & $1(2 \cdot 0)$ & $4(2 \cdot 2)$ & $7(1.9)$ & $5(1 \cdot 6)$ & $12(1 \cdot 8)$ & $>0.3$ & $>0 \cdot 3$ & $>0 \cdot 3$ & \\
\hline PPD pos. & $5(3 \cdot 8)$ & $2(3 \cdot 9)$ & $7(3 \cdot 8)$ & $20(5 \cdot 6)$ & $12(3.9)$ & $32(4 \cdot 8)$ & $>0 \cdot 3$ & $>0 \cdot 3$ & $>0 \cdot 3$ & \\
\hline BRM pos. & 0 & $1(2 \cdot 0)$ & $1(0 \cdot 5)$ & 0 & $7(2 \cdot 3)$ & $7(1 \cdot 1)$ & - & $>0 \cdot 3$ & $>0 \cdot 3$ & \\
\hline \multicolumn{11}{|c|}{ Have you dyed your hair? } \\
\hline All $(n=852)$ & $379(76 \cdot 7)$ & $73(20 \cdot 4)$ & $452(53 \cdot 1)$ & & & & & & & $<0.001$ \\
\hline TDM pos. & $7(1 \cdot 8)$ & $2(2 \cdot 7)$ & $9(2 \cdot 0)$ & $4(3 \cdot 5)$ & $4(1 \cdot 4)$ & $8(2 \cdot 0)$ & $0 \cdot 291$ & $>0 \cdot 3$ & $>0 \cdot 3$ & \\
\hline PPD pos. & $21(5 \cdot 5)$ & $2(2 \cdot 7)$ & $23(5 \cdot 1)$ & $5(4 \cdot 3)$ & $12(4 \cdot 2)$ & $17(4 \cdot 3)$ & $>0 \cdot 3$ & $>0 \cdot 3$ & $>0.3$ & \\
\hline BRM pos. & 0 & $2(2 \cdot 7)$ & $2(0 \cdot 4)$ & $1(0 \cdot 9)$ & $6(2 \cdot 1)$ & $7(1 \cdot 8)$ & 0.233 & $>0.3$ & 0.092 & \\
\hline \multicolumn{11}{|c|}{ Have you had a tourist tattoo made on you? } \\
\hline All $(n=850)$ & $30(6 \cdot 1)$ & $18(5 \cdot 0)$ & $48(5 \cdot 6)$ & & & & & & & $>0.3$ \\
\hline TDM pos. & $1(3 \cdot 3)$ & $1(5 \cdot 6)$ & $2(4 \cdot 2)$ & $9(1.9)$ & $5(1.5)$ & $14(1 \cdot 7)$ & $>0.3$ & $0 \cdot 268$ & $0 \cdot 277$ & \\
\hline PPD pos. & $2(6 \cdot 7)$ & $2(11 \cdot 1)$ & $4(8 \cdot 3)$ & $24(5 \cdot 2)$ & $12(3 \cdot 5)$ & $36(4 \cdot 5)$ & $>0 \cdot 3$ & $0 \cdot 152$ & $0 \cdot 276$ & \\
\hline BRM pos. & $1(3 \cdot 3)$ & $1(5 \cdot 6)$ & $2(4 \cdot 2)$ & 0 & $7(2 \cdot 1)$ & $7(0 \cdot 9)$ & 0.061 & $>0.3$ & 0.087 & \\
\hline \multicolumn{11}{|c|}{$\begin{array}{l}\text { Do you work or have you worked with textiles } \\
\text { (a) in production of textiles/dyes? }\end{array}$} \\
\hline All $(\mathrm{n}=849)$ & $8(1 \cdot 6)$ & $7(2 \cdot 0)$ & $15(1 \cdot 8)$ & & & & & & & $>0.3$ \\
\hline TDM pos. & 0 & 0 & 0 & $10(2 \cdot 1)$ & $6(1 \cdot 7)$ & $16(1 \cdot 9)$ & $>0.3$ & $>0.3$ & $>0.3$ & \\
\hline PPD pos. & $1(12 \cdot 5)$ & 0 & $1(6 \cdot 7)$ & $24(5 \cdot 0)$ & $14(4 \cdot 0)$ & $38(4 \cdot 6)$ & $>0.3$ & $>0.3$ & $>0.3$ & \\
\hline BRM pos. & 0 & 0 & 0 & 0 & $8(2 \cdot 3)$ & $8(1 \cdot 0)$ & - & $>0 \cdot 3$ & $>0 \cdot 3$ & \\
\hline \multicolumn{11}{|c|}{ (b) where finished textiles are handled? } \\
\hline All $(n=845)$ & $68(13 \cdot 9)$ & $14(3 \cdot 9)$ & $82(9 \cdot 7)$ & & & & & & & $<0.001$ \\
\hline TDM pos. & 0 & $1(7 \cdot 1)$ & $1(1 \cdot 2)$ & $10(2 \cdot 4)$ & $5(1.5)$ & $15(2 \cdot 0)$ & $>0.3$ & $0 \cdot 216$ & $>0.3$ & \\
\hline PPD pos. & $3(4 \cdot 4)$ & $2(14 \cdot 3)$ & $5(6 \cdot 1)$ & $21(5 \cdot 0)$ & $11(3 \cdot 2)$ & $32(4 \cdot 2)$ & $>0.3$ & 0.088 & $>0.3$ & \\
\hline BRM pos. & 0 & 0 & 0 & 0 & $8(2 \cdot 3)$ & $8(1 \cdot 0)$ & - & $>0.3$ & $>0.3$ & \\
\hline
\end{tabular}

W, women; M, men; TDM, textile dye mix; pos., positive; PPD, para-phenylenediamine; BRM, black rubber mix.

without skin problems $(P=0 \cdot 211$; Table 3$)$. The $O R$ for reporting skin problems, adjusted for age, sex and childhood eczema, associated with TDM was 1.9 (95\% CI 0.57-5.6). BRM allergy was rare and no evident association with skin problems was found. There was a tendency for BRM-positive patients not to have used hair dye $(P=0.092)$ and to have had temporary 'black henna' tattoos $(P=0.087)$.
Two per cent had worked with textiles in dye works, in textile factories or in the manufacture of textile dyes or as a supplier of textile dyes. Three per cent of those with textilerelated skin problems had worked in textile factories compared with $1 \%$ without skin problems to textiles $(P=0 \cdot 163)$. Ten per cent had worked with finished textiles, e.g. as a dressmaker, in a fabric or garment shop or in the laundry business, 
Table 4 Odds ratios (OR), confidence intervals (CI) and P-values for predictors of a positive answer to the question about having textilerelated skin problems in a multiple logistic regression. The 'baseline odds' refers to a 40-year-old male without childhood eczema and with a negative para-phenylenediamine (PPD) reaction

\begin{tabular}{lllr}
\hline Factor & OR & $95 \% \mathrm{CI}$ & P-values \\
\hline Baseline odds & 0.10 & $0.07-0.14$ & $<0.001$ \\
Sex (female vs. male) & 1.95 & $1.33-2.92$ & $<0.001$ \\
Age (per 10 years) & 1.14 & $1.02-1.28$ & 0.022 \\
Childhood eczema & 2.26 & $1.49-3.40$ & $<0.001$ \\
PPD positive & 2.14 & $1.01-4.31$ & 0.039 \\
\hline
\end{tabular}

$14 \%$ of the women compared with $4 \%$ of the men $(\mathrm{P}<0.001)$. Fourteen per cent of those reporting skin problems had been working with finished textiles compared with $9 \%$ without problems to textiles $(P=0.069)$. No association was found between contact allergy to TDM, PPD, BRM or formaldehyde and work in textile factories or with finished textiles. The results are shown in Table 5 .

The most frequently involved skin sites were the legs, followed by the trunk, arms and neck, and the areas around the armpit and the groin (results not shown). No association was found between textile-related skin problems on a particular body area and contact allergy to the TDM, PPD, BRM or formaldehyde.

\section{Analysis of the nonrespondents}

Thirteen per cent of the patients were not asked to complete the questionnaire. No important differences could be seen in sex, age and studied contact allergies between these patients and the patients who answered the questionnaire. Data on the two groups of patch tested patients are shown in Table 1.

\section{Discussion}

Individual patients with contact allergy to DDs are regularly traced by patch testing with commercially available textile patch test screening series. On the other hand, there is little knowledge of the clinical relevance of positive patch tests to DDs. In the previous study performed at the department in Malmö, $1 \cdot 5 \%$ of 3325 patch tested patients tested positively to the TDM. ${ }^{8}$ The European Society of Contact Dermatitis recommends a sensitizer to be considered for inclusion in the baseline patch test series when routine testing of patients with suspected contact dermatitis results in a contact allergy rate exceeding $0.5-1 \% .{ }^{10}$ The contact allergy rate found in the Malmö study raised the question of whether or not a TDM should be included in the baseline series. In the present study $2 \%$ of 982 consecutively patch tested patients tested positively to the TDM (Table 1). Accordingly, the contact allergy rate found in this study supports the idea of including the TDM in the baseline series. However, besides the contact allergy rates, other factors such as clinical relevance have to be considered before inclusion in a baseline series. ${ }^{10}$ Thus, the present study was undertaken to clarify the connection between textilerelated clinical manifestations and contact allergy to DDs.

History, clinical findings and exposure are the major elements in the assessment of clinical relevance in an allergic individual. The questioning on exposure and assessment of its significance for the dermatitis under investigation is easily

Table 5 The answers to the question 'Have you ever had a rash/itch that you suspect is caused by textiles?' divided by sex, age, occupation and contact allergies

\begin{tabular}{|c|c|c|c|c|c|c|c|c|c|c|}
\hline & \multicolumn{10}{|c|}{ Answers to the question on textile-related problems } \\
\hline & \multicolumn{3}{|l|}{ Yes, n (\%) } & \multicolumn{3}{|c|}{ No/don't know, n (\%) } & \multicolumn{4}{|c|}{ P-values, positive answers vs. negative } \\
\hline & W & M & $\mathrm{W}+\mathrm{M}$ & W & $\mathrm{M}$ & $\mathrm{W}+\mathrm{M}$ & $\mathrm{W}$ & M & $\mathrm{W}+\mathrm{M}$ & $\mathrm{W} / \mathrm{M}$ \\
\hline Sex & $112(22 \cdot 5)$ & $43(11 \cdot 9)$ & $155(18 \cdot 1)$ & $385(77 \cdot 5)$ & $317(88 \cdot 1)$ & $702(81 \cdot 9)$ & & & & $<0.001$ \\
\hline Age (years) & & & & & & & & & $0 \cdot 15$ & \\
\hline $0-30$ & $26(17 \cdot 9)$ & $2(3 \cdot 0)$ & $28(13 \cdot 3)$ & $119(82 \cdot 1)$ & $64(97 \cdot 0)$ & $183(86 \cdot 7)$ & & & & \\
\hline $30-50$ & $39(22 \cdot 7)$ & $26(15 \cdot 1)$ & $65(18 \cdot 9)$ & $133(77 \cdot 3)$ & $146(84 \cdot 9)$ & $279(81 \cdot 1)$ & & & & \\
\hline $50-100$ & $47(12 \cdot 3)$ & $47(12 \cdot 3)$ & $60(20 \cdot 5)$ & $133(73.9)$ & $107(87 \cdot 7)$ & $240(79 \cdot 5)$ & $0 \cdot 214$ & 0.036 & 0.091 & \\
\hline Childhood eczema & $42(38.5)$ & $9(21 \cdot 4)$ & $51(33 \cdot 8)$ & $91(23 \cdot 8)$ & $42(13 \cdot 2)$ & $133(19 \cdot 0)$ & 0.003 & $0 \cdot 160$ & $<0.001$ & \\
\hline \multicolumn{11}{|l|}{ Exposure } \\
\hline Textile factory & $4(3 \cdot 6)$ & $1(2 \cdot 4)$ & $5(3 \cdot 3)$ & $4(1 \cdot 0)$ & $6(1.9)$ & $10(1 \cdot 4)$ & $0 \cdot 081$ & $>0.3$ & $0 \cdot 163$ & \\
\hline Finished textiles & $19(17 \cdot 1)$ & $2(4 \cdot 9)$ & $21(13 \cdot 8)$ & $49(12 \cdot 9)$ & $12(3 \cdot 8)$ & $61(8 \cdot 8)$ & $0 \cdot 276$ & $>0.3$ & 0.069 & \\
\hline \multicolumn{11}{|l|}{ Contact allergy } \\
\hline All neg. & $102(91 \cdot 1)$ & $39(90 \cdot 7)$ & $141(91 \cdot 0)$ & $363(94 \cdot 3)$ & $300(94 \cdot 6)$ & $663(94 \cdot 4)$ & $0 \cdot 272$ & $0 \cdot 296$ & $0 \cdot 138$ & \\
\hline TDM pos. & $3(2 \cdot 7)$ & $2(4 \cdot 7)$ & $5(3 \cdot 2)$ & $8(2 \cdot 1)$ & $4(1 \cdot 3)$ & $12(1 \cdot 7)$ & $>0.3$ & $0 \cdot 153$ & $0 \cdot 211$ & \\
\hline PPD pos. & $9(8 \cdot 1)$ & $3(7 \cdot 0)$ & $12(7 \cdot 7)$ & $17(4 \cdot 4)$ & $11(3 \cdot 5)$ & $28(4 \cdot 0)$ & $0 \cdot 148$ & $0 \cdot 227$ & 0.057 & \\
\hline BRM pos. & 0 & $1(2 \cdot 3)$ & $1(0 \cdot 6)$ & $1(0 \cdot 3)$ & $7(2 \cdot 2)$ & $8(1 \cdot 1)$ & $>0.3$ & $>0.3$ & $>0.3$ & \\
\hline All pos. & 0 & $1(0 \cdot 3)$ & 0 & 0 & 0 & $1(0 \cdot 1)$ & $>0 \cdot 3$ & - & $>0.3$ & \\
\hline Formaldehyde pos. & $2(1 \cdot 8)$ & 0 & $2(1 \cdot 3)$ & $12(3 \cdot 1)$ & $9(2 \cdot 8)$ & $21(3 \cdot 0)$ & $>0.3$ & $>0.3$ & $>0.3$ & \\
\hline
\end{tabular}

W, women; M, men; neg., negative; TDM, textile dye mix; pos., positive; PPD, para-phenylenediamine; BRM, black rubber mix. 
biased when the contact allergy is known to the dermatologist and the patient. To use a questionnaire answered by the patient prior to patch testing makes it possible to avoid the bias that the knowledge of a contact allergy to the chemicals of interest could give, and hence one would obtain information on various factors more objectively. In the present study we, therefore, used a questionnaire to investigate the association between textile problems and contact allergy to TDM and chemically related substances. Thus, the present study was not an epidemiological investigation aimed at determining the true prevalence of textile dermatitis, but a study in which an epidemiological instrument, the questionnaire, was used to explain a possible connection between patient-reported textilerelated skin problems and contact allergies to a TDM and chemically related substances, formaldehyde and various risk factors.

As several crease-resistant textiles contain textile finish resins of the formaldehyde type, patients with contact allergy to formaldehyde would possibly report more textile-related skin problems. However, no statistically significant association could be found between contact allergy to formaldehyde, sex or textile-related skin problems (Table 5). These findings are supported by an article by Scheman et al. ${ }^{11}$ who consider that most clothing today does not contain enough free formaldehyde to cause skin problems in formaldehyde-allergic individuals.

The question 'Have you ever had a rash/itch that you suspect is caused by textiles?' did not pick out the patients testing positively to the TDM, whereas the study demonstrated contact allergy to PPD to be an independent risk factor for textile-related skin problems (Table 4). On the other hand, although not statistically significant, 3\% of the patients suspecting textiles as a cause of their skin problems tested positively to the TDM and/or its ingredients compared with $2 \%$ of the patients answering negatively to this question. Furthermore, a statistically highly significant association was seen between the patients testing positively to both PPD and TDM.

From our clinical experience there are obvious cases with textile dermatitis and contact allergy to the DDs included in the present TDM. There may be several explanations for the fact that no statistically significant association was found in the present study between the patients answering that they had had a rash/itch possibly caused by textiles and having allergic test reactions to the TDM. One important reason may be that only $2 \%$ of the patients who answered the questionnaire tested positively to the TDM. The low prevalence of patients with contact allergy to the DDs tested makes it difficult to demonstrate a statistically significant association between the test results and reported skin problems due to textiles. More positive reactors may have been found by patch testing with the eight DDs at higher concentrations in the mix. In commercially available textile series the concentrations of the DDs are double those used in the TDM, with the exception of DB 106 and 124, which are commercially available at 10 times higher concentrations. In the present study only two patients tested positively to DB 106 and 124 (Table 2). One of these patients answered positively to the question about textile-related skin problems. Many studies on contact allergy to DDs also emphasize DB 106 and 124 as the DDs of most interest. $^{12,13}$

Furthermore, only 13 of the 20 TDM-positive patients tested positively to any of the ingredients in the mix. Possible explanations could be that the penetration into the skin of the TDM is higher, compared with the penetration of the ingredients when tested separately. Other possible explanations are a compound allergy, additive or synergistic effects of the different substances, as has been demonstrated when testing other mixes such as fragrance mix. ${ }^{14,15}$

To obtain a higher number of participating patients the study was performed at departments in both Malmö and Leuven. The patch testing of the patients followed the routine of the respective departments, and accordingly the methodologies used at the two centres differed. However, because of our experience, the patch test results using Finn Chambers ${ }^{\circledR}$ and Van der Bend Square Chambers ${ }^{\circledR}$ were comparable. Furthermore, only the patch test reactions registered on day 3 or 4 , the common reading occasion, could be used for registration in the present study. A late reading on day 7 may have detected more patients with contact allergy to the DDs. In Malmö, the reading on day 7 revealed three more patients with allergic reactions to the TDM and four patients with positive reactions to at least one ingredient in the mix (results not shown). These findings support the importance of late readings, as reported in several studies. ${ }^{16,17}$

Another explanation for the fact that no association was found between the patients answering that they had had a rash/itch possibly caused by textiles, and having allergic test reactions to the TDM, may be that the DDs used are not the best screening dyes to detect clinically relevant textile-related skin problems caused by DDs. This statement is supported by a study by Hatch et al., ${ }^{18}$ who demonstrated that the DDs to which the patients were patch test allergic when testing with commercial patch test series, were only infrequently identified among the DDs found in the fabrics suspected to be the cause of the skin lesions. However, in our clinics, we have seen patients with textile-related skin problems due to contact allergy to the DDs used in our study, especially to DB 106 and 124 (unpublished observations).

As mentioned before, PPD historically has been considered to be a screening allergen for textile dye dermatitis ${ }^{7}$ and the results in the present study raise the question of whether or not contact allergy to PPD is a better indicator for textilerelated skin problems than the TDM. Contact allergy to PPD may also indicate that the patient has been sensitized by hair dye, temporary 'black henna' tattoo dye or by PPD derivatives in BRM. However, the present study could not demonstrate any statistically significant association between contact allergy to PPD and having used hair dye or having had temporary tattoos (Table 3). On the other hand, some other studies consider PPD to be a good screening agent for contact allergy to hair dye, but not for DD sensitivity. ${ }^{12,19}$ Nevertheless, 
simultaneous sensitivity to PPD and DDs, especially DO 3, has been described repeatedly. ${ }^{19,20}$ In the present study PPD-positive patients significantly more often tested positively to both the TDM and DO 3 separately $(\mathrm{P}<0.001$ and $\mathrm{P}<0.019$, respectively). Possible explanations for simultaneous allergy to PPD and DDs could be cross-reactivity or sensitization to a common metabolite. ${ }^{20,21}$ Accordingly, at least some of the patients allergic to the TDM may initially have been sensitized to PPD and then reacted to DDs due to cross-reactivity, or they may have been sensitized due to exposure to a common metabolite, rather than sensitized due to primary exposure to DDs in textiles.

Synthetic material was regarded as the most common textile to give rash/itch, followed by wool, cotton and silk. The good properties of silk, especially for atopic children, have been described by Ricci et al. ${ }^{22}$ and silk has been recommended as a useful tool in the management of atopic dermatitis. The wellknown relationship between patients having a history of eczema as a child and intolerance to wool ${ }^{23}$ was also found in the present study. It is more difficult to explain why women reacted significantly more often to wool than men and more seldom to cotton. However, as many textiles are produced from mixed natural and synthetic fibres today, some of the patients answering the questionnaire may believe that they use pure cotton textiles when, in reality, they use clothes containing mixed natural and synthetic material. This circumstance may lead to more unreliable answers to this question.

When evaluating the overall answers to the questionnaire, women more often had eczema as a child, they more often dyed their hair and more often had worked with textiles. In the present study, women also tended to suspect textiles as a cause of skin problems more often than men. Possible explanations could be that women are more prone to skin irritation, or perhaps are more observant of skin manifestations than the average man, and that women have a tendency to wear more tight-fitting underwear made from synthetic textile materials, leading to increased friction and sweating. Women also use more hair dyes, cosmetics and other skin-care products which can cause skin irritation and/or contact allergies. According to several studies, women are more prone to become sensitized to DDs. ${ }^{1,2,24}$ However, the present study could not demonstrate any statistically significant sex difference in patch test results to the TDM or to PPD, although women suspecting intolerance to synthetic materials were statistically more often allergic to PPD compared with women without skin problems from such textiles. Furthermore, there was a tendency for PPD-positive patients as a whole to report intolerance to synthetic fibres more often than PPD-negative patients.

Most skin sites have been involved in textile dermatitis. ${ }^{4,25}$ In this study no statistically significant associations were found between skin site and contact allergy to TDM or chemically related substances.

Childhood eczema was found to be an independent, statistically highly significant risk factor for textile-related skin problems (Table 4). Although the question 'Have you had eczema as a child?' may overestimate the prevalence of atopic eczema in childhood, ${ }^{26}$ it is highly unlikely that this will change the conclusion that childhood eczema is a risk factor for textile-related skin problems. Previous childhood eczema most likely reflects general skin sensitivity, as no association could be found between childhood eczema and contact allergy either to TDM, or to PPD or BRM (Table 3).

Although not statistically significant, there was a tendency for patients working with production or with finished textiles to have more textile-related problems than patients answering negatively to these questions, but no statistically significant association was found between working with textiles or dyes and contact allergy to TDM, PPD or BRM (Tables 3 and 5). Nowadays very little textile manufacturing is found in Belgium or Sweden, while there is a lot of occupational exposure to finished textile products.

In conclusion, $18 \%$ of 858 dermatitis patients suspected textiles to be the cause of their past or present skin problems. Female sex, increasing age, previous childhood eczema and contact allergy to PPD were found to be important risk factors with an OR $\sim 2$. Contact allergy to TDM was not demonstrated as a significant risk factor, but simultaneous contact allergy to PPD and TDM was statistically highly significant. The present TDM was currently inferior to PPD to trace textile-related skin problems; thus TDM with its present composition is not recommended for inclusion in a baseline patch test series. A change in the composition may justify such an inclusion. Ongoing studies with simultaneous patch testing with the DDs in different concentrations will possibly give us more information on optimal patch test concentrations for tracing patients with contact allergy to DDs. However, for the time being, whenever a patient has a positive patch test reaction to PPD, the history must be scrutinized for the possibility of textilerelated skin problems, and testing with textile dyes should be considered.

\section{Acknowledgments}

The authors thank Monica Andersson, Karin Olsson, Lena Persson and Lotta Ralving-Thorsson for skilful assistance with the handling of the questionnaire and patch testing of the Swedish patients. The work was supported by grants from the Swedish Asthma and Allergy Association, the Fyrbodal Research Institute and the Research and Development Council of Fyrbodal, the county of Västra Götaland, Sweden.

\section{References}

1 Hatch KL, Maibach HI. Textile dye allergic contact dermatitis prevalence. Contact Dermatitis 2000; 42:187-95.

2 Lazarov A. Textile dermatitis in patients with contact sensitization in Israel: a 4-year prospective study. J Eur Acad Dermatol Venereol 2004; 18:531-7.

3 Gasperini M, Farli M, Lombardi P, Sertoli A. Contact dermatitis in the textile and garment industry. In: Current Topics in Contact Dermatitis (Frosch PJ, ed.). Berlin: Springer-Verlag, 1989; 326-9. 
4 Seidenari S, Manzini BM, Danese P. Contact sensitization to textile dyes: description of 100 subjects. Contact Dermatitis 1991; 24:253-8.

5 Hatch KL, Maibach HI. Textile dye dermatitis. J Am Acad Dermatol 1995; 32:631-9.

6 Giusti F, Mantovani L, Martella A, Seidenari S. Hand dermatitis as an unsuspected presentation of textile dye contact sensitivity. Contact Dermatitis 2002; 47:91-5.

7 Hatch KL, Maibach HI. Textile dye dermatitis. A review. J Am Acad Dermatol 1985; 12:1079-92.

8 Ryberg K, Isaksson M, Gruvberger B et al. Contact allergy to textile dyes in southern Sweden. Contact Dermatitis 2006; 54:313-21.

9 Fregert S (ed.). Manual of Contact Dermatitis, 2nd edn. Copenhagen: Munksgaard, 1981:71-6.

10 Bruze M, Conde-Salazar L, Goossens A et al. Thoughts on sensitizers in a standard patch test series. The European Society of Contact Dermatitis. Contact Dermatitis 1999; 41:241-50.

11 Scheman AJ, Carroll PA, Brown KH, Osburn AH. Formaldehyderelated textile allergy: an update. Contact Dermatitis 1998; 38:332-6.

12 Pratt M, Taraska V. Disperse blue dyes 106 and 124 are common causes of textile dermatitis and should serve as screening allergens for this condition. Am J Contact Dermat 2000; 11:30-41.

13 Uter W, Geier J, Hausen BM. Contact allergy to Disperse Blue 106/124 mix in consecutive German, Austrian and Swiss patients. Contact Dermatitis 2003; 48:286-7.

14 Johansen JD, Skov L, Volund A et al. Allergens in combination have a synergistic effect on the elicitation response: a study of fragrance-sensitized individuals. Br J Dermatol 1998; 139:264-70.

15 Frosch PJ, Rastogi SC, Pirker C et al. Patch testing with a new fragrance mix - reactivity to the individual constituents and chemical detection in relevant cosmetic products. Contact Dermatitis 2005; 52:216-25.
16 Bruze M, Hedman H, Bjorkner B, Moller H. The development and course of test reactions to gold sodium thiosulfate. Contact Dermatitis 1995; 33:386-91.

17 Goon AT, Isaksson M, Zimerson E et al. Contact allergy to (meth)acrylates in the dental series in southern Sweden: simultaneous positive patch test reaction patterns and possible screening allergens. Contact Dermatitis 2006; 55:219-26.

18 Hatch KL, Motschi H, Maibach HI. Disperse dyes in fabrics of patients patch test-positive to disperse dyes. Am J Contact Dermat $2003 ; \mathbf{1 4}: 205-12$.

19 Koopmans AK, Bruynzeel DP. Is PPD a useful screening agent? Contact Dermatitis 2003; 48:89-92.

20 Goon AT, Gilmour NJ, Basketter DA et al. High frequency of simultaneous sensitivity to Disperse Orange 3 in patients with positive patch tests to para-phenylenediamine. Contact Dermatitis 2003; 48:248-50.

21 Seidenari S, Mantovani L, Manzini BM, Pignatti M. Cross-sensitizations between azo dyes and para-amino compound. A study of 236 azo-dye-sensitive subjects. Contact Dermatitis 1997; 36:91-6.

22 Ricci G, Patrizi A, Bendandi B et al. Clinical effectiveness of a silk fabric in the treatment of atopic dermatitis. Br J Dermatol 2004; 150:127-31.

23 Bendsoe N, Bjornberg A, Asnes H. Itching from wool fibres in atopic dermatitis. Contact Dermatitis $1987 ; 17: 21-2$.

24 Balato N, Lembo G, Patruno C, Ayala F. Prevalence of textile dye contact sensitization. Contact Dermatitis 1990; 23:111-12.

25 Lisboa C, Barros MA, Azenha A. Contact dermatitis from textile dyes. Contact Dermatitis 1994; 31:9-10.

26 Stenberg B, Lindberg M, Meding B, Svensson A. Is the question 'Have you had childhood eczema?' useful for assessing childhood atopic eczema in adult population surveys? Contact Dermatitis 2006; 54:334-7. 